\title{
Immunohistochemical investigation of P16, P53 and Ki-67's prognostic values in diffuse large B-Cell lymphomas
}

\author{
Baran $\mathrm{M}^{1}$, Canoz $\mathrm{O}^{1}$, Altuntas $\mathrm{H}^{2}$, Sivgin $\mathrm{S}^{3}$, Cetin $\mathrm{M}^{3}$, Yay $\mathrm{A}^{4}$, Ketenci $\mathrm{S}^{3}$ \\ Department of Pathology, Erciyes University, Medical Faculty, Kayseri, Turkey. \\ munevverbaran@erciyes.edu.tr
}

\begin{abstract}
AIM: The aim of this study is to determine the immunohistochemical properties of Ki-67, P53 expression and loss of P16, and to assess their relationship with both clinical parameters and patient survival in DLBCL. METHOD: Forty patients, diagnosed at the Pathology Department of our institute with nodal DLBCL were selected as the study group. The relationship between P16, P53, Ki-67 expressions and clinical and laboratory parameters like age, gender, performance status, Eastern Cooperative Oncology Group (ECOG), clinical stage, presence of B-symptoms, bone marrow involvement, International Prognostic Index (IPI) score, lactate dehydrogenase (LDH) level, extranodal extension, relapse, C-reactive protein (CRP), sedimentation, number of leukocytes in patients and patient survival were then statistically evaluated.

RESULTS: Our results display no statistically significant correlation between P53 expression and loss of P16, Ki-67 proliferation index and clinical parameters and overall survival $(p>0.05)$. The only statistically significant relationship was between loss of P16 and stage $(p<0.05)$. Furthermore, no statistically significant relationship was found between patient survival and clinical parameters $(p>0.05)$.

CONCLUSION: According to the results of our study, the loss of P16, P53 gene expression and Ki-67 proliferation index have no effect on life expectancy of patients with DLBCL (Tab. 2, Fig. 2, Ref. 29). Text in PDF www.elis.sk. KEY WORDS: diffuse large B-cell lymphomas, P16, P53, Ki-67, prognosis.
\end{abstract}

\section{Introduction}

Diffuse large B-cell lymphoma (DLBCL) is a disease characterized by a high degree of heterogeneity in immunophenotype, pathogenesis, and clinical response. It is the most common type as it comprises $30 \%$ of all non-Hodgkin's lymphomas (1). Unbalanced cell proliferation and death are universal features of malignancies involving DLBCLs (2).

Presumably, in addition to clinical parameters, the alterations within oncogenes and tumor suppressor genes have been well documented and have been shown to drive the prognosis, biological behavior of the tumor and new treatment regimens for DLBCL (3). P53 governs major defenses against tumor growth and promotes

${ }^{1}$ Department of Pathology, Erciyes University, Medical Faculty, Kayseri, Turkey, ${ }^{2}$ Department of Pathology, Erciyes University School of Medicine, Kayseri, Turkey, ${ }^{3}$ Department of Medical Biology, Erciyes University School of Medicine, Kayseri, Turkey, ${ }^{4}$ Department of Hematology and Oncology, Erciyes University Medical Faculty, Kayseri, Turkey, ${ }^{5}$ Department of Histology and Embryology, Erciyes University, Faculty of Medicine, Kayseri, Turkey, and ${ }^{6}$ Department of Internal Medicine-Rheumatology, Erciyes University Medical Faculty, Kayseri, Turkey

Address for correspondence: M. Baran, PhD, Department of Pathology, Medicine Faculty, University of Erciyes, 38039 Kayseri, Turkey. Phone: +352.207.6666, Fax: +352.4377627

Acknowledgement: This work was supported by a research grant from the Scientific Research Projects Unit (TSD-09-958). cellular DNA repair, apoptosis (4). In normal cells, p53 isoforms were associated with physiological functions regulated by different genes. In cancer cells, abnormal expression of p53 isoforms contributes actively to cancer formation and progression (5). Ki67 detects nuclear antigens associated with cell proliferation. Actively proliferating cells were identified in paraffin section called Ki67 proliferative index, which represents the active growth fraction of the tumor. As various studies confirmed the correlation of Ki67 index with tumor grade and clinical behavior of the tumors, it became the routine part of various tumor workup especially of lymphoid neoplasms (6). Cell cycle progression is controlled by a series of cyclin-dependent kinases (CDKs) which are complexed with specific cyclins while the disruption of regulatory pathways is an important feature of DLBCL (7).

Clinical prognostic factors, as well as biological markers are mandatory to individualize the treatment process. Owing to the heterogeneity of the clinical course observed in DLBCL patients, the ability to predict outcome is vital but remains challenging (8). Most of the prognostic models are based on the clinical features. One of the most important clinical predictors of survival in DLBCL patients is the International Prognostic Index (IPI). Although the IPI was developed in 1993, even today, it is still the most important tool to predict response to treatment for DLBCL, and its prognostic value in DLBCL patients has been validated (9). However, one of the shortcomings of this prediction approach is that the molecular abnormalities of tumor cells are not encompassed by IPI (10). In 
Tab. 1. Number and percentage of clinical parameters of patients.

\begin{tabular}{|c|c|c|c|}
\hline & & Number & $\%$ \\
\hline \multirow{2}{*}{ Sex } & Male & 23 & 57.5 \\
\hline & Female & 17 & 42.5 \\
\hline \multirow{2}{*}{ Age } & $60<$ & 19 & 47.5 \\
\hline & $60>$ & 21 & 52.5 \\
\hline \multirow{4}{*}{$\begin{array}{l}\text { Performance } \\
\text { status }\end{array}$} & 0 & 3 & 7.5 \\
\hline & 1 & 32 & 80 \\
\hline & 2 & 4 & 10 \\
\hline & 3 & 1 & 2.5 \\
\hline \multirow{2}{*}{ B-symptoms } & Present & 9 & 22.5 \\
\hline & Absent & 5 & 12.5 \\
\hline \multirow{2}{*}{ Bone marrow involvement } & Present & 2 & 5 \\
\hline & Absent & 23 & 57.5 \\
\hline \multirow{2}{*}{$\begin{array}{l}\text { Extranodal } \\
\text { disease }\end{array}$} & Present & 8 & 20 \\
\hline & Absent & 11 & 27.5 \\
\hline \multirow{2}{*}{ Recurrence } & Present & 4 & 10 \\
\hline & Absent & 6 & 15 \\
\hline \multirow{2}{*}{ LDH levels } & Normal & 30 & 75 \\
\hline & Elevated & 10 & 25 \\
\hline \multirow[b]{2}{*}{ Survival } & Alive & 31 & 77.5 \\
\hline & Dead & 9 & 22.5 \\
\hline \multirow{4}{*}{ Stage } & 1 & 3 & 7.5 \\
\hline & 2 & 6 & 15 \\
\hline & 3 & 11 & 27.5 \\
\hline & 4 & 4 & 10 \\
\hline \multirow{5}{*}{ IPI } & 0 & 8 & 20 \\
\hline & 1 & 12 & 30 \\
\hline & 2 & 15 & 37.5 \\
\hline & 3 & 4 & 10 \\
\hline & 4 & 1 & 2.5 \\
\hline
\end{tabular}

the light of this information, the aim of the study was to investigate the relationship between patient survival, clinical factors and biological markers including different expression patterns, and to determine the prognostic significance of cell cycle regulatory molecules P16, P53, and Ki-67, a cell proliferation marker, in a study group of 40 DLBCL patients.

\section{Material and methods}

\section{Participants}

Tissue samples used in this study were taken from 40 patients with histologically proven diagnosis of nodal DLBCL at Pathology Department of our institute. Institutional ethics committee approval for human studies was obtained prior to the study (Ethics Committee Decision No. 09/206). Paraffin-embedded tissue samples with de novo DLBCL were immunohistochemically analyzed for P53, Ki-67 and P16 monoclonal antibody expressions. All clinical, laboratory and follow-up data were obtained from the hospital records or patients' charts. Clinical stages were based on the modified Ann-Arbor classification system (11).

\section{Immunohistochemistry}

All histopathologic samples were re-evaluated and confirmed to have DLBCL according to World Health Organization classifications. Formalin-fixed and paraffin embedded blocks were cut into
Tab. 2. Univariate and multivariate biomarker expression, IPI score, parameters associated with IPI in all patients with DLBCL.

\begin{tabular}{|c|c|c|c|c|}
\hline & \multicolumn{2}{|l|}{ Univariate } & \multicolumn{2}{|l|}{ Multiple } \\
\hline & $\mathrm{HR}(95 \% \mathrm{CI})$ & $\mathrm{p}$ & $\mathrm{HR}(95 \% \mathrm{CI})$ & $\mathrm{p}$ \\
\hline$\underline{\text { IPI }}$ & $1.98(1.04-3.78)$ & 0.038 & $1.98(1.04-3.78)$ & 0.038 \\
\hline \multicolumn{5}{|l|}{ Age } \\
\hline$<60$ & 1.00 & - & - & - \\
\hline$>60$ & $2.35(0.56-9.89)$ & 0.244 & - & - \\
\hline \multicolumn{5}{|c|}{ Performance } \\
\hline 0 & 1.00 & - & - & - \\
\hline 1 & $26611.91(0.00-4.68)$ & 0.960 & - & - \\
\hline 2 & $38316.37(0.00-6.76)$ & 0.958 & - & - \\
\hline 3 & $0.986(0.00-2.71)$ & 1.00 & - & - \\
\hline \multicolumn{5}{|l|}{$\overline{\mathrm{LDH}}$} \\
\hline$<460$ & 1.00 & - & - & - \\
\hline$>460$ & $2.62(0.62-11.11)$ & 0.191 & - & - \\
\hline \multicolumn{5}{|c|}{$\begin{array}{l}\text { Extranodal } \\
\text { involvement }\end{array}$} \\
\hline Absence & 1.00 & - & - & - \\
\hline Presence & $0.40(0.02-6.80)$ & 0.523 & - & - \\
\hline \multicolumn{5}{|l|}{ Stage } \\
\hline 1 & 1.00 & - & - & - \\
\hline 2 & $0.746(0.15-3.71)$ & 0.720 & - & - \\
\hline \multicolumn{5}{|l|}{$\mathrm{Ki}-67$} \\
\hline 0 & 1.00 & - & - & - \\
\hline 1 & $1.19(0.20-7.18)$ & 0.848 & - & - \\
\hline 2 & $0.24(0.02-2.66)$ & 0.246 & - & - \\
\hline 3 & $0.47(0.07-3.32)$ & 0.445 & - & - \\
\hline \multicolumn{5}{|l|}{ P53 } \\
\hline 0 & 1.00 & - & - & - \\
\hline 1 & $1.67(0.31-9.09)$ & 0.560 & - & - \\
\hline 2 & $3.71(0.68-20.44)$ & 0.133 & - & - \\
\hline \multicolumn{5}{|l|}{ P16 } \\
\hline 0 & 1.00 & - & - & - \\
\hline 1 & $2.26(0.26-19.78)$ & 0.463 & - & - \\
\hline 2 & $0.51(0.07-4.25)$ & 0.534 & - & - \\
\hline
\end{tabular}

sections of 5- $\mu \mathrm{m}$ thickness. These sections were pretreated according to the manufacturer's recommendations. Primary antibodies applied are listed as follows: P53 (Thermo Scientific Fremont, CA 94538, USA, dilution 1/100), Ki-67 (Thermo Scientific, Rockford, USA dilution 1/100), P16 (CINtec, Heidelberg, Germany, ready to use). Subsequent development of the antibody reaction was done by Anti-Polyvalent HRP kit (Thermo Scientific, USA). Immunoreactivity was then visualized with diaminobenzidine staining, and the sections were counterstained with hematoxylin and mounted. A tissue section of patients with DLBCL that was known to contain P53, Ki-67 and P16 markers served as a positive control in each course of staining. The negative control was incubated with blocking buffer alone instead of the primary antibody. A slide was scored positive only if it had all P53, P16 and Ki-67 primer antibody nuclear staining.

$\mathrm{P} 16$ protein expression was considered normal only if P16 nuclear immunostaining was present in all areas. Partial or complete absence of nuclear staining in a tissue section was considered to be a loss of P16 protein expression only if the interspersed nuclei of reactive cells (lymphocytes, endothelial cells) displaying P16 expression were observed (12). 
$602-608$

\section{Immunohistological scoring}

Three categories were defined for P16 expression: negative ( $0 \%$ ), weak positive $(<10 \%$ positive tumor cells) and positive ( $\geq 10 \%$ positive stained tumor cells) (13). P53 expression was evaluated as follows: $1+$ score when weak positive reactions were found in under $10 \%$ of the tumor cells, $2+$ score when positive reactions were found in $10-50 \%$ of the tumor cells, $3+$ score when positive reactions were found $50-90 \%$ of the tumor cells and $4+$ score when more than $90 \%$ of the tumor exhibited positive reactions (14).

Ki-67 expression was evaluated as follows: $1+$ score when weak positive reactions were found in $1-25 \%$ of the tumor cells, $2+$ score when positive reactions were found in $25-50 \%$ of the tumor cells, $3+$ score when positive reactions were found $50-75 \%$ of the tumor cells, and $4+$ score when more than $75 \%$ of the tumor exhibited positive reactions (15). The immunohistochemical staining for P53 and Ki-67 was assigned the score of 0 when only negative reactions were found inside the tumor cells.

\section{Statistical analyses}

Clinical parameters and results were studied in retrospect. Statistical analyses were performed using SPSS 15.0 software pack- age. The survival was estimated using the Kaplan-Meier method, and statistical significance was determined by the long-range test. Correlations between clinical parameters and immunohistochemical parameters (Ki-67, P53 and P16) were searched by Pearson's chi-squared $\left(\mathrm{X}^{2}\right)$ test. $\mathrm{p}$ values of $<0.05$ were considered to indicate significance. Furthermore, statistical relationships between results of P $53 \%$, Ki-67 \% and clinical parameters were analyzed by Sperman's Rho correlations. Univariate and multivariate analyses were used to assess the prognostic significance of P53, Ki-67, P16 expressions, IPI scores and parameters associated with IPI for overall survival.

\section{Results}

\section{Patients characteristic}

Forty patients were investigated to detect correlations between the protein expressions, clinical parameters and survival. Twentythree of patients were male (57.5\%) and 17 were female (42.5\%), and their age ranged from 20 to 87 years, while the mean age of patients was found to be 60.5. Main clinical parameters of DLBCL patients are summarized in Table 1. Clinical parameters of remaining patients were not available in their files.
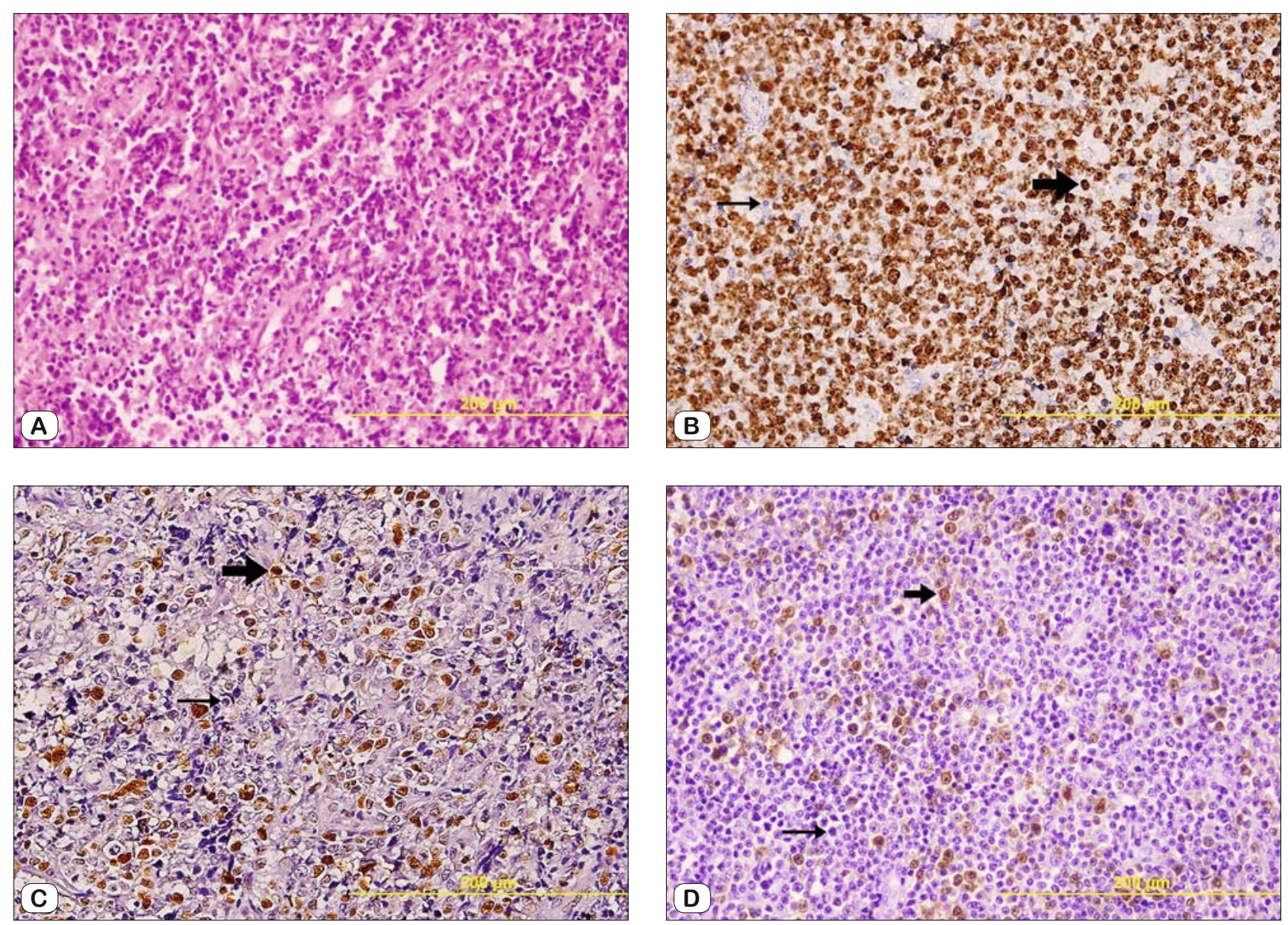

Fig. 1. (A) Hematoxylin-eosin staining of DLBCL. (B) Immunohistochemical staining showing positivity for Ki-67. (C) P53 and (D) P16 in DLBCL. Thin arrow; negative staining cell and thick arrow; positive staining cell. Original magnification x40. 

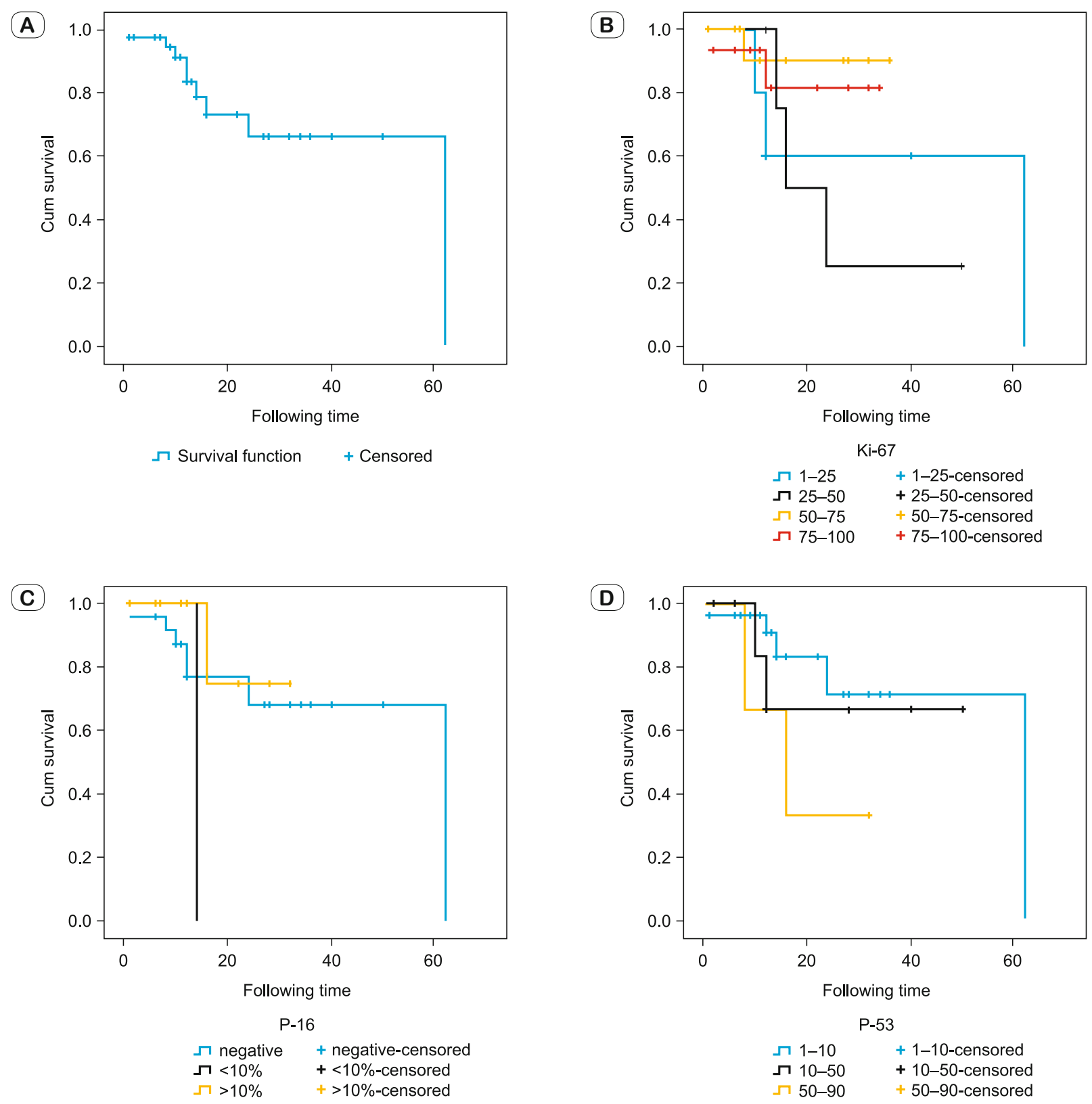

Fig. 2. (A) The relationship between survival and follow-up period. (B) The relationship between Ki-67 expression and survival ( $p=0.398)$. (C) The relationship between P16 expression and survival $(p=0.553)$. (D) The relationship between p53 expression and survival $(p=0.277)$. No significant difference is found between the survival curves and biologic markers.

\section{Immunohistochemical findings}

No P16 nuclear protein expression was observed in $26(65 \%)$ DLBCL patients, while $11(27.5 \%)$ displayed $\geq 10 \%$ loss of P16 expression, and 3 (7.5\%) displayed $<10 \%$. When P53 expression was scored as $+1,+2$ or +3 , relevant patient proportions were found to be $72.5 \%, 20 \%$ and $7.5 \%$, respectively. When Ki-67 nuclear expression according to proliferative activity was grouped as +1 , $+2,+3$ and +4 , relevant patient proportions were found to be 12.5 $\%, 17.5 \%, 32.5 \%$ and $37.5 \%$, respectively. A representative positive staining of these markers is shown in Figure 1.
Effect of prognostic factors on survival

Survival analysis was also performed, based on the information on follow-up periods, which ranged between 1 and 62 months. The median for follow-up periods of surviving patients was 16.97 months. Nine (22.5\%) of the patients died because of lymphoma. The remaining 31 (77.5\%) patients were alive. The overall survival was calculated as the time between the dates of diagnosis and death. The expression of P53, P16, Ki-67 in DLBCL patients was determined by immunohistochemistry, and results were evaluated according to the Kaplan-Meier relation 


\section{2-608}

method with overall survival and follow-up time. Survival curves of these markers are shown in Figure 2. When effects of overall survival on expression of P16, P53, Ki-67 and follow-up time of patients were inspected, no statistically significant relationship was found $\mathrm{p}>0.05)$.

\section{Biological markers and their relation to the other prognostic pa- rameters}

In order to determine the relationship between parameters involved in the prognosis of DLBCL, Sperman's Rho correlation analysis was applied. P16 was not added to these variables as the loss of P16 expression is a different assessment. As for clinical parameters and biological markers, negative correlations between age and follow-up time ( $\mathrm{p}=0.011)$, and IPI and follow-up time ( $\mathrm{p}$ $=0.025$ ) were found. Moreover, positive correlations were found between IPI and disease stage $(\mathrm{p}=0.001)$, and IPI and age $(\mathrm{p}=$ 0.008). Significant differences were also detected between CRP and IPI ( $p=0.032)$, CRP and sedimentation $(p=0.037)$, and number of leukocytes and sedimentation $(\mathrm{p}=0.011)$. No significant difference was detected between Ki-67 \% and P53 \% expressions and any of clinical parameters.

Univariate and multivariate analysis results of P53, Ki-67, P16 expressions, IPI scores and parameters associated with IPI for overall survival are also shown in Table 2. Multivariate IPI score has been shown as an independent risk factor. One-unit increase in IPI score was 1.98 (hazard ratio) times more risky for survival $(\mathrm{p}<0.05)$ while multivariate analysis using the Cox regression model could not be significant in other comparisons according to our results.

Moreover, the Pearson's chi-squared $\left(\mathrm{X}^{2}\right)$ method was used to analyze the relation between clinical parameters and expression status of cell cycle proteins (P53 and P16) and proliferation index (Ki-67). While the results displayed a significant relationship between P16 and disease stage $(\mathrm{p}=0.013)$, no significant relationship between other parameters $(p>0.05)$ was found. No correlations among biological markers themselves and between biological markers and overall survival, or follow-up time were found to have statistical significance.

\section{Discussion}

DLBCL is a disease with a high degree of heterogeneity in morphology, clinical presentation and outcome of therapy. It is clear that differences in the clinical features and treatment responses of DLBCL are due to molecular heterogeneity that underlies the aggressiveness of the disease and related tumor progression (16). This heterogeneity was appreciated through various morphologic, immunologic and cytogenetic features to assess the prognostic value of single biomarkers (17). In terms of response to treatment and prognosis, DLBCL is from a heterogeneous group, and its prognostic factors have been determined (18). The expression of oncogenes and tumor suppressor markers were examined in these studies in addition to clinical parameters (19). Cell cycle regulatory molecules were reported to be associated with the generation or prognosis of malignant lymphoma (2). Numerous such biological prognostic markers have been proposed as candidates for prognosis in patients with DLBCL. This study was aimed at conforming the expression of cell cycle regulatory molecules and their prognostic implications in 40 patients with de novo DLBCL. Prognostic markers are assayed by a variety of methods, most commonly by morphology and immunohistochemistry. In present study, we used a immunohistochemical method for P53, Ki-67 and P16 biomarkers to try to accurately predict the disease's outcome for the test group patients.

P53 is a tumor suppressor gene and is observed in malignant tumors. Only a few of studies have been conducted on the role of P53 protein in DLBCL, and they have produced conflicting evidence $(20,21,22)$. Imamura et al (23) reported that P53 expression was up to $30 \%$ in aggressive B-cell lymphoma, while Ishioka et al (24) showed that P53 expression could be an important prognostic factor in non-Hodgkin's lymphoma. Ichikowa et al (25) observed that P53 alterations were common in clinical stage 4-B of cell lymphoma, while in the studies of Piris and colleague, P53 immunoreactivity was found to be an independent factor in survival (20). Zhang et al (3) found shorter survival for patients with P53 expression in DLBCL. In contrast, other studies assessing the prognostic significance of P53 overexpression in DLBCL found no association with overall survival $(14,26)$. Present study, similarly to the Rujirojindakul et al (27), did not demonstrate statistical correlation between p53 expression and age, sex, LDH level, and B symptoms in patients with DLBCL. The findings in our study suggest no relation between P53 expression and survival. We believe that this difference in outcomes may depend on the sensitivity of the employed immunohistochemical method and cut-off value assigned to study.

$\mathrm{Ki}-67$ expression as a nuclear marker for increased cell proliferation predicts poor response to chemotherapy and shorter survival of the patients. According to Zang et al (3), low Ki-67 index $(<10 \%)$ was found to have a tendency to a shorter related survival compared to high proliferation activity, but this relationship was not statically significant. Concerning Ki-67 expression, however, it has been shown that high $\mathrm{Ki}-67$ proliferation index is also a poor prognostic marker for DLBCL (26). Although these studies indicated that survival of patients was related with increased or decreased expression of Ki-67, no relationship between survival and Ki-67 expression was found in our study.

P16 is encoded at the INK4a/ARF locus of chromosome 9p21. P16 is a key regulator at the G1-S check point of the cell cycle, and an alteration in its functions plays a critical role in tumorigenesis. In lymphoid malignancies, P16 gene silencing, mainly induced by gene methylation, is frequently found in Hodgkin and non-Hodgkin lymphomas, and has been associated with tumor progression (28). According to Gronbaek et al (29), a concurrent disruption of P16, P14 and P53 pathways acts as an independent negative prognostic factor in aggressive nonHodgkin's lymphoma. Those showed a significantly of the p16/ p14/p53 markers $(-/-/+)$ shorter overall survival only in the GC phenotype in DLBCL divided two group (13). Individual bio- 
markers may provide prognostic information for patients with DLBCL. In this study, there was no significant correlation between p16 and survival. Due to the complexity of the underlying mechanisms related to the loss of P16 expression, more detailed studies are necessary to understand the prognostic importance of the latter loss.

The prognosis of a tumor is determined by a combination of host and tumor-related factors. Clinical factors such as stage and LDH constitute rough reflections of the underlying tumor biology. Thus, it is likely that assessment of tumor biology would provide additional information and improve the prognostic precision of the prognostic index, like IPI. Such clinical prognostic parameters, including IPI, are used to stratify patients according to the overall prognosis (8). Zhou et al (9) supported the idea that IPI is one of the most important clinical predictors of survival in DLBCL patients. As no significant difference was found among other clinical parameters in our study, significant correlations between IPI and age, and IPI and stage were detected. Moreover, multivariate analysis showed that IPI score is an independent risk factor related to survival. The major finding of our retrospective study was that P16 and disease stage were statistically important in determining the prognosis of patients with DLBCL. Our study shows that the relation between P16 and stage is a predictive prognostic variable in interpreting individualized clinical results in patients with DLBCL.

\section{Conclusion}

In summary, we investigated whether survival, clinical factors and biological markers were related in patients with DLBCL. Biologic markers used in this study were found to be irrelevant independent predictors, except for P16. P16 status may demonstrate a late event in progression of lymphoma. Yet, P16 loss should be further proven by molecular techniques in the future studies. To confirm our findings, both further large-scale studies and a standard cut-off value set for biomarkers are needed. At present, with more global approaches like potential molecular techniques, it may be possible to understand better the biological and prognostic significance of biological markers.

\section{References}

1. Menon MP, Pittaluga S, Jaffe ES. The histological and biological spectrum of diffuse large B-cell lymphoma in the World health organization classification. Cancer J 2012; 18: 411-240.

2. Sanchez-Beato M, Sanchez-Aguilera A, Piris MA. Cell cycle deregulation in B-cell lymphomas. Blood 2003; 101: 1220-1235.

3. Zhang A, Ohshima K, Sato K, Kanda M, Suzumiya J, Shimazaki $\mathrm{K}$ et al. Prognostic clinicopathologic factors, incluiding immunologic expression in diffuse large b-cell lymphomas. Pathology International 1999; 97: 1043-1052.

4. Lu TX, Young KH, Xu W, Li JY. TP53 dysfunction in diffuse large B-cell lymphoma. Critical Reviews in Oncology/Hematology 2016; 97 : $47-55$.
5. Marcel V, Dichtel-Danjoy ML, Sagne C, Hafsi H, Ma D, Ortiz-Cuaran $\mathrm{S}$ et al. Biological functions of p53 isoforms through evolution: lessons from animal and cellular models. Cell Death Differ 2011; 18 : 1815-1824.

6. Haroon S, Hashmi AA, Khurshid A, Kanpurwala MA, Mujtuba S, Malik B et al. Ki67 index in breast cancer: correlation with other prognostic markers and potential in Pakistani patients. Asian Pac J Cancer Prev 2013; 14: 4353-4358.

7. Malumbres M, Barbacid M. Cell cycle, CDKs and cancer: a changing paradigm.Nat Rev Cancer 2009; 9: 153-166.

8. Salles G, de Jong D, Xie W, Rosenwald A, Chhanabhai M, Gaulard $\mathbf{P}$ et al. Prognostic significance of immunohistochemical biomarkers in diffuse large B-cell lymphoma: a study from the Lunenburg lymphoma biomarker consortium. Blood 2011; 117: 7070-7078.

9. Zhou Z, Sehn LH, Rademaker AW, Gordon LI, Lacasce AS, CrosbyThompson A et al. An enhanced international prognostic index (NCCNIPI) for patients with diffuse large B-cell lymphoma treated in the rituximab era. Blood 2014; 123: 837-842.

10. Alizadeh AA, Eisen MB, Davis RE, Ma C, Lossos IS, Rosenwald A et al. Distinct types of diffuse large B-cell lymphoma identified by gene expression profiling. Nature 2000; 403: 503-511.

11. Lister TA, Crowther D, Sutcliffe SB, Glatstein E, Canellos GP, Young RC et al. Report of a committee convened to discuss the evaluation and staging of patients with Hodgkin's disease. Cotswolds meeting J Clin Oncol 1989; 7: 1630-1636.

12. Geradts J, Wilson PA. High frequency of aberrant P16INK4A expression in human breast cancer. Am J Pathol 1996; 149: 15-20.

13. Paik JH, Jeon YK, Park SS, Kim YA, Kim JE, Huh J et al. Expression and prognostic implications of cell cycle regulatory molecules, p16, p21, p27, p14 and p53 in germinal centre and non-germinal centre Blike diffuse large B-cell lymphomas. Histopathology 2005; 47: 281-291.

14. Sohn SK, Jung JT, Kim DH, Kim JG, Kwak EK, Park Ti et al. Prognostic significance of bcl-2, bax, and p53 expression in diffuse large B-cell lymphoma.Am J Hematol 2003; 73: 101-107.

15. Van Imhoff GW, Boerma EJ, Van der Holt B, Schuuring E, Verdonck LF, Kluin-Nelemans HC et al. Prognostic impact of germinal center-associated proteins and chromosomal breakpoints in poor-risk diffuse large B-cell lymphoma.J Clin Oncol 2006; 24: 4135-4142.

16. Menon MP, Pittaluga S, Jaffe ES. The histological and biological spectrum of diffuse large B-cell lymphoma in the World health organization classification. Cancer J 2012; 18: 411-420.

17. Lossos IS, Morgensztern D. Prognostic biomarkers in diffuse large B-cell lymphoma. J Clin Oncol 2006; 24: 995-1007.

18. Kucukzeybek BB, Bener S, Calli AO, Paksoy TD, Payzin B. Prognostic Significance of Bcl-2 and p53 Protein Expressions and Ki67 Proliferative Index in Diffuse Large B-cell Lymphoma. Turk J Hematol 2013; 30: 275-282

19. Ertan Y, Soydan S, Tombuloglu M, Cagirgan S, Donmez A, Saydam G et al. Mitotic Actıvity, P53 And Bcl-2 Protein Immunoreactıvity Difference Between Morphological Varıants And Subtypes Of Diffuse Large B Cell Lymphoma. Ege Medicine Journal 2006; 45: 5-11.

20. Piris MA, Pezella F, Martinez-Montero JC, Orradre JL, Villuendas R, Sanchez-Beato $\mathbf{M}$ et al. p53 and bcl-2 expression in high-grade B-cell lymphomas: correlation with survival time. Br J Cancer 1994; 69: 337-341. 


\section{2-608}

21. Ahn M, Kim H, Kim I, Park JK, Ki M, Park C. P53 protein expression and its prognostic importance in patients with nodal non-Hodgkin's lymphoma. J Korean Med Sci 2000; 15: 59-64.

22. Charalambous GK, Gomatos IP, Konstadoulakis MM, Messaris EG, Manouras AJ, Apostolou AE et al. Protein expression of bax, bcl2, and P53 in patients with non-Hodgkin's gastric lymphoma: prognostic significance. World J Surg 2000; 24: 608-614.

23. Imamura J, Miyoshi I, Koeffler HP. P53 in hematologic malignancies. Blood 1994; 84: 2412-2421.

24. Ishioka C, Frebourg T, Yan Y-X, Vidal M, Friend SH, Schmidt S et al. Screening patients for heterozygous p53 mutations using a functional assay in yeast. Nat Genet 1993; 5: 124-129.

25. Ichikawa A, Hotta T, Takagi N, Tsushita K, Kinoshita T, Nagai H et al. Mutations of p53 gene and their relation to disease progression in B-cell lymphoma. Blood 1992; 79: 2701-2717.
26. Sanchez E, Chacon I, Plaza MM, Munoz E, Cruz MA, Martinez B et al. Clinical outcome in diffuse large B cell lymphoma is dependent on relationship between different cell-cycle regulator proteins. J Clin Oncol 1998; 5: 1931-1939.

27. Rujirojindakul P, Aiempanakit K, Kayasut K, Lekhakula A, Sriplung H. No prognostic impact of p53 and P-glycoprotein expression in patients with diffuse large B-cell lymphoma. ISRN Oncol 2011; 2011: 1-6.

28. Takino H, Okabe M, Li C, Ohshima K, Yoshino T, Nakamura S et al. p16/INK4a gene methylation is a frequent finding in pulmonary MALT lymphomas at diagnosis. Modern Pathology 2005; 18: 1187-1192.

29. Gronbaek K, de Nully Brown P, Moller MB, Nedergaard T, Ralfkiaer E, Moller P et al. Concurrent disruption of P16INK4a and the ARF-p53 pathway predicts poor prognosis in aggressive non-Hodgkin's lymphoma. Leukemia 2000; 14: 1727-1735. 